\title{
Fabrication of Gelatin/Bioactive Glass Hybrid Scaffolds for Bone Tissue- Engineering
}

\author{
S. Borrego-González ${ }^{1}$, J. Becerra ${ }^{2,3}$ and A. Díaz-Cuenca ${ }^{1,3}$ \\ ${ }^{1}$ Instituto de Ciencia de Materiales de Sevilla (ICMS), Centro Mixto CSIC-Universidad de Sevilla, Sevilla, España \\ ${ }^{2}$ Departamento de Biología Celular, Genética y Fisiología, Facultad de Ciencias,Universidad de Málaga, Málaga, España \\ ${ }^{3}$ Networking Research Center on Bioengineering, Biomaterials and Nanomedicine (CIBER-BBN), Spain
}

\begin{abstract}
In this work, hybrid scaffold materials composed of gelatin and Bioactive Glass (BG) have been fabricated. BG particulates in the ternary system $\mathrm{SiO}_{2}-\mathrm{CaO}-\mathrm{P}_{2} \mathrm{O}_{5}$ have been synthesized initially using the sol-gel method. The gelatin/BG scaffolds were shaped by a freeze-drying process obtaining homogeneous and reproducible final macroporous structures. BG particulates precursor and the final hybrid macroporous structures (scaffolds) were characterized using Field Emission Scanning Electron Microscopy (FE-SEM), Energy Dispersive X-ray Analysis (EDX), X-ray diffraction (XRD) and thermal analysis. Finally, the scaffolds were essayed in Simulated Body Fluid (SBF) in vitro showing a bioactive response.
\end{abstract}

Keywords - Gelatin, Bioactive Glass, Bone Tissue Engineering, Macroporous scaffold.

\section{INTRODUCTION}

Population aging and enhance one's quality of life is demanding new approaches and therapies for bone reparation and regeneration. At present, bone substitutes are often required to replace defected tissue generated by disease, aging or trauma [1]. Tissue Engineering (TE) is a very promising option which has the potential to overcome the problem providing the development of constructs to be implanted for the repair or regeneration of injured or damaged tissues. As well as in natural tissues, cells, extracellular matrix (ECM) and signaling molecules are the basic elements of TE. Bone is a tissue whose special architecture has allowed a fast development of its associated TE. The fundamental constituents of bone are cells and the extracellular matrix (ECM). This ECM is a biphasic or hybrid matrix composed of organic and inorganic elements. The organic phase is mainly formed by collagen type I fibbers which correspond to the $90 \%$ of the total bone protein. The main component of the inorganic phase is calcium carbonate phosphate in the form of spindle or plate-shaped crystalline hydroxyapatite $\left(\mathrm{Ca}_{18.3-0.7}\left(\mathrm{PO}_{4}\right)_{4.3}\left(\mathrm{HPO}_{4}, \quad \mathrm{CO}_{3}\right)_{1.7}\right.$ $\left.\left(2 \mathrm{OH}, \mathrm{CO}_{3}\right)_{0.15}\right)$ [2]. It is this combination of the calcium phosphate mineral phase, collagen fibers and living cells which gives the bone its outstanding properties of hardness, toughness and self-renewal capacity [3].
The fabrication of synthetic bone extracellular matrix using calcium phosphates and natural polymers such as collagen or gelatin has leaded to the appearance of an entire field of biomaterials research. Gelatin (denatured form of collagen) has greater availability and it is easier and cheaper to obtain than collagen. Gelatin keeps collagen chemistry and amino acids polymeric architecture and it is readily reabsorbable by the body.

Calcium phosphates and bioceramic materials as tricalcium phosphate (TCP) or synthetic hydroxyapatite (HA) have a composition very close to the natural mineral of the bone. These materials are biocompatible which have been proved to enhance the bone growth $[3,4]$. However, studies in vivo have shown that bioactive glasses are the materials which are fixed more efficiently and rapidly in bone regeneration [5]. Bioactive glasses were discovered by Larry Hench's in 1969 when he found that a particular glass composition (45S5 Bioglass $\left.{ }^{\circledR}\right)$ was able to form a chemical bond with bone [6]. Hench defined as bioactive material which one has the ability to bond and fix spontaneously in the body with the living tissue without the formation of a fibrous interface layer or capsule [7].

In bone TE the scaffold must act as a three-dimensional temporary template to guide the bone repair stimulating the natural regenerative mechanisms of the human body. The scaffolds should have a high porosity in the macropore range $(100-500 \mu \mathrm{m})$ to facilitate cellular migration and vascularization, a proper mechanical integrity and biocompatibility, and their degradation rate should match the rate of neotissue formation. The scaffold should promote osteoconductivity (bone cell attach along the material surface from the bone-implant interface) and osteoinductivity (stimulates new bone formation) [8].

In this work, the fabrication of macroporous architectures based on gelatin/bioactive glass have been investigated using freeze-drying processing techniques. Different processing parameters as the gelatin hydrogel concentration, the processing cooling rate and the molding container configuration have been modified to study their influence in the final volume fraction porosity $[10,11]$ and pore architecture [12-14] of the full gelatin (BG free) materials. From this preliminary study, selected parameters were used to 
prepare the gelatin/BG hybrid scaffolds. Final scaffolds were characterized in terms of composition, porosity, macrostructure and bioactivity in vitro.

\section{MAterials AND METHODS}

\section{A. Bioactive glass synthesis}

The Bioactive Glass (BG) particulate precursor was prepared using the reactants ratios as reported by Yan et al. [15]. Ethanol absolute (AnalaR Normapur) and 0,5 M HCl solution (Panreac, PA-ACS-ISO 37\%) were mixed. The reactants $\mathrm{Ca}\left(\mathrm{NO}_{3}\right)_{2} \cdot 4 \mathrm{H}_{2} \mathrm{O}$ (Sigma-Aldrich), triethyl phosphate (TEP, $\left(\mathrm{C}_{2} \mathrm{H}_{5} \mathrm{O}\right)_{3} \mathrm{PO}$, Sigma-Aldrich) and tetraethyl orthosilicate (TEOS, $\mathrm{C}_{8} \mathrm{H}_{20} \mathrm{O}_{4} \mathrm{Si}$, Alfa Aesar) were added with a molar ratio of $\mathrm{Si} / \mathrm{Ca} / \mathrm{P}$ of $80: 15: 5$ (or $\mathrm{Si} / \mathrm{Ca} / \mathrm{P}=$ $76: 13: 11$ in weight ratio). The mixture (sol) was undergone an evaporation-induced self-assembly (EISA) process to form a gel. The gel was aged at $75^{\circ} \mathrm{C}$ and then heating at $700^{\circ} \mathrm{C}$ to obtain the final $\mathrm{BG}$ product which was ground to prepare the final particulate precursor.

\section{B. Preparation of the Gelatin/BG hybrid scaffolds}

The gelatin was dissolved in de-ionized distilled water at a concentration of $2.5 \%(\mathrm{w} / \mathrm{w})$ and stirred for $1 \mathrm{~h}$ at $40^{\circ} \mathrm{C}$. Amounts of particulate BG were blended with gelatin water solution in $50 \% \mathrm{w} / \mathrm{w}$, Fig. 1a. The mixture was homogenized by stirring for 30 minutes. The resulting solution was poured into a Petri dish and kept at $4^{\circ} \mathrm{C}$ to produce a gel (Fig. 1b). A punch was used to obtain the scaffolds with $12 \mathrm{~mm}$ diameter and $2 \mathrm{~mm}$ height. The structures were cross-

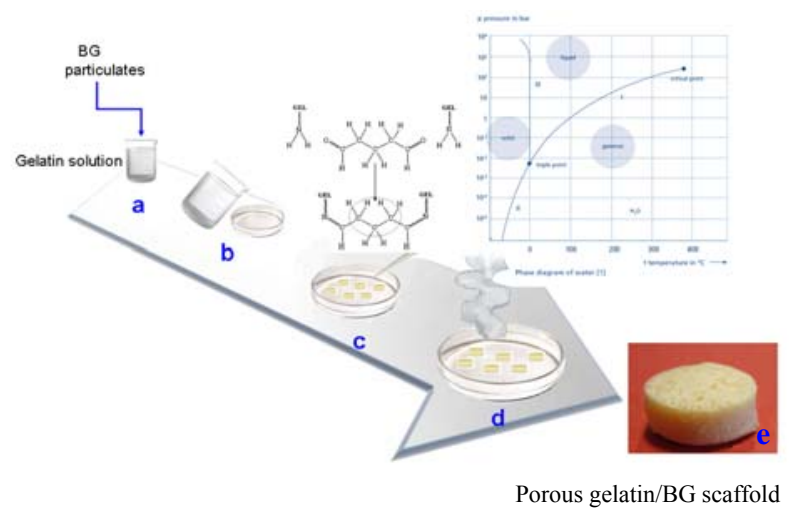

Fig.1 Schematic diagram of the scaffolds fabrication. Amounts of particulate MBG were blended with gelatin water solution (a). Pouring into a Petri dish and shaping the scaffolds (b). Crosslinking (c). Freeze-drying (d). Final porous gelatin/BG scaffold (e) linked by immersion in $0.25 \% \mathrm{v} / \mathrm{v}$ glutaraldehyde (GA) aqueous solution (Fig. 1c) and freeze-dried with a freeze rate of $1^{\circ} \mathrm{C} / \mathrm{min}$ to $-20^{\circ} \mathrm{C}$ and held at this temperature under a vacuum of $0.04 \mathrm{mbar}$ for 24 hours (Fig. 1d).

\section{$C$. Characterization of the $B G$ particulates and the Gelatin/BG scaffolds}

The particle size distribution (PSD) of the BG particulates was measured using the laser scattering method. A MalvernSizer Laser Diffraction (LD) instrument using active beam length of $2.4 \mathrm{~mm}$ and a $300-\mathrm{RF}$ lens was used. Xray diffraction (XRD) analysis was performed with a PANanalytical X'Pert PRO diffractometer using $\mathrm{Cu}-\mathrm{K}_{\alpha}$ radiation $(\lambda=0.154187 \mathrm{~nm})$. The diffractometer was operated at $45 \mathrm{kV}$ and $40 \mathrm{~mA}$. Wide-angle X-ray diffraction (WXRD) patterns were recorded using a step size of $0.02^{\circ}$ and $800 \mathrm{~s}$ exposure time. BG particulate precursor and scaffolds were evaluated with an HITACHI S-4800 Field Emission Gun Scanning Electron Microscope (FEG-SEM). The compositional analysis of the BG was performed by XRay Fluorescence (XRF) using the Spectrometer Panalytical (AXIOS model). Thermo gravimetric (TG) and differential scanning calorimetry (DSC) analysis were carried out using an automatic thermal analyzer system (model SDT Q600). The total porosity of the hybrid scaffolds, $P$ was calculated by the Eq. 1 .

$$
P=1-\frac{\rho_{\text {scaffold }}}{\rho_{\text {solid }}}=1-\rho_{\text {relative }},
$$

The density of the scaffold $\left(\rho_{\text {scaffold }}\right)$ was determined from the mass and dimensions of the final material pieces. The density of the solid $\left(\rho_{\text {solid }}\right)$ was estimated using the quantitative analysis of the each component and the solid density values for the gelatin $\left(\rho_{\text {gelatin }}=1.037 \mathrm{~g} \cdot \mathrm{cm}^{-3}\right)$ [24] and BG $\left(\rho_{B G}=2.321 \mathrm{~g} \cdot \mathrm{cm}^{-3}\right.$, estimated using quantitative analysis). The assessment of the scaffolds bioactivity was carried out by soaking in Simulated Body Fluid (SBF) [16]. Each piece was immersed in $15 \mathrm{ml}$ of SBF in polyethylene container for 3 days at $36.5^{\circ} \mathrm{C}$. After the treatment, the scaffolds were washed thrice in distilled water and freeze-dried. Bioactivity was assessed by FE-SEM, EDX and XRD analysis.

\section{RESUlTS AND DISCUSSION}

\section{A. Characterization of the $B G$ particulates}

Particle size distribution of the BG is shown in Fig. 2a. The plot shows a bimodal distribution (pink) which was deconvoluted using a Gaussian function by the Origin software. Deconvolution results (blue) show two symmetric dis- 


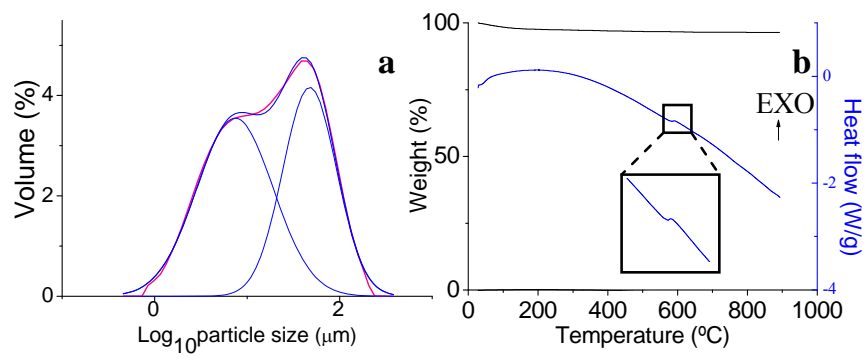

Fig. 2 Particle size distribution (a) and DTA curve (b) of the BG precursor particulates

tributions of 54 and 46 area \%, with maximum at 7 and 47 $\mu \mathrm{m}$ respectively. The XRD analysis confirmed that the BG particulates were XRD amorphous as no diffraction peaks were observed apart from a broad band between 18 and $40^{\circ}$ $(2 \theta)$ as it has been reported previously $[17,18]$. The quantitative analysis of the $\mathrm{BG}$ indicates a final composition of $87 \mathrm{SiO}_{2} / 10 \mathrm{CaO} / 3 \mathrm{P}_{2} \mathrm{O}_{5}$ wt. \%. The elemental quantitative analysis indicates that a lower percentage of $\mathrm{P}$ and $\mathrm{Ca}$ than expected from the from the reactants precursor ratio. The TGA (Fig. 2b) of the BG shows a mass loss of only $2 \%$ which would correspond to the removal of the material moisture. The DSC (Fig. 2b) shows a typical endothermic event at $580^{\circ} \mathrm{C}$ characteristic of the glass transition temperature. Both, DSC showing the glass transition temperature and the amorphous diffraction pattern confirm the obtention of a glass material.

\section{B. Characterization of the Gelatin/BG hybrid scaffolds}

The final macropore structure of the gelatin scaffolds (BG free) is presented in Fig. 3. The results show that the macropore size decreases with the increasing amount of gelatin (Fig. 3a and b). Also, the pore size decreases with the increasing freezing rate (Fig $3 \mathrm{a}$ and $\mathrm{c}$ ). An orientated pore alignment has been achieved using shaping moulds consisting on the combination of various materials which have different thermal conductivities [12] (Fig. 3a and d). From this preliminary work, a selection of parameters was made to prepare the gelatin/BG hybrid scaffolds. These parameters were $2.5 \mathrm{wt} . \%$ gelatin concentration, a freezing rate of $1{ }^{\circ} \mathrm{C} / \mathrm{min}$ and the mould consisting on polystyrene (PS). The total porosity of the hybrid gelatin/BG scaffolds was measured as $95 \% \pm 0.427$. FE-SEM observations and EDX analysis of the total cross-section of these scaffolds are shown in Fig. 4. The FE-SEM images indicate an homogeneous macroporous structure in terms of size and macropore shape or morphology. The size of the macropore

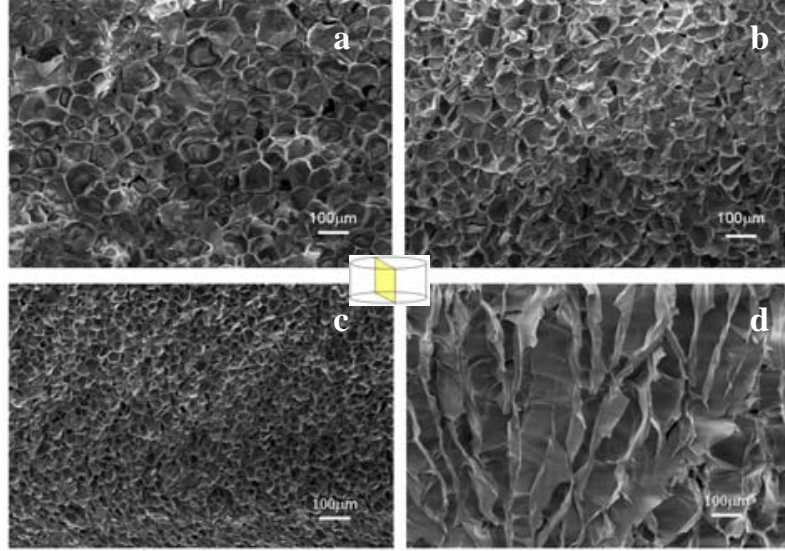

Fig. 3 FE-SEM images of full gelatin system study. 2.5\% gelatin, cooling rate of $1^{\circ} \mathrm{C} / \mathrm{min}$ and mould of polystyrene (PS) (a), $5 \%$ gelatin, $1^{\circ} \mathrm{C} / \mathrm{min}$ and mould of PS (b), gelatin $2.5 \%$, freezing rate of $2{ }^{\circ} \mathrm{C} / \mathrm{min}$ and mould of PS (c) and $2.5 \%$ gelatin, $1^{\circ} \mathrm{C} / \mathrm{min}$ and mould of PS and aluminum (d)

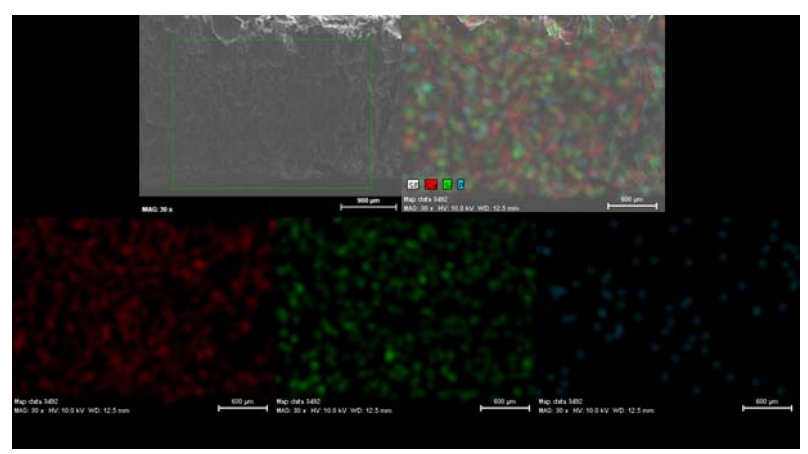

Fig. 4 FE-SEM images of the gelatin/BG scaffold and EDX mapping of the scaffolds

was measured in the range from 100 to $500 \mu \mathrm{m}$. Hence, both final total porosity and macropore size of the fabricated scaffolds were in the required values generally agreed in the literature, of a porosity of $50 \%$ or higher and macropore size of $100 \mu \mathrm{m}$ or higher, to permit tissue ingrowth. The EDX analysis of $\mathrm{Ca}, \mathrm{Si}$ and $\mathrm{P}$ showed that the BG components are equally distributed within the scaffold crosssection.

\section{Bioactivity test in vitro}

Fig. 5a shows a FE-SEM image of the hybrid scaffold after 3 days in SBF treatment. As can be seen in the image, needle-shaped crystal aggregates characteristics of hydroxyapatite are formed on the surface of the scaffolds. The crystal size was measured by image analysis showing values of about $200 \mathrm{~nm}$. Also, the XRD pattern obtained after SBF (Fig. 5b) matched well with the hydroxyapatite phase accor- 

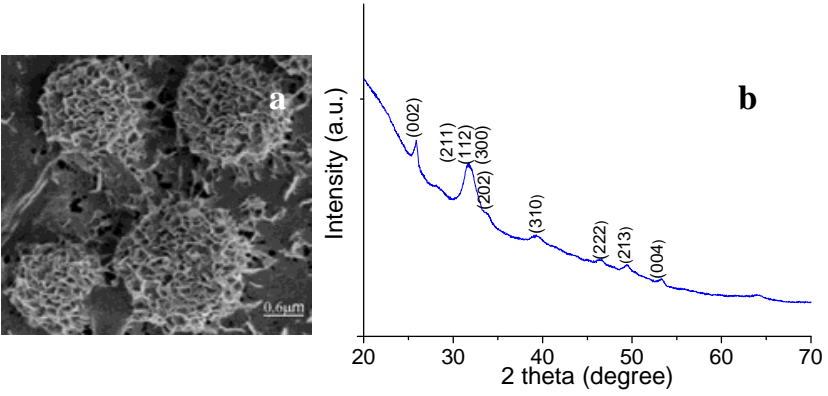

Fig. 5 FE-SEM images of the immersed scaffolds in SBF showing the hydroxyapatite crystals aggregates (a); and the WXRD analysis (b)

ding to the ICCD database (JCPDS 046-0905). The broad asymmetric peak with high intensity around 30-35 $2 \theta$ may consists of four overlapping peaks, which could be assigned to HA characteristic triplet for the reflections (211), (112), and (300), with the (202) reflection appearing as a faint shoulder at $33.92 \theta[18,20]$. A control bioactivity experiment using a full gelatin scaffold (BG free) was performed. In this experiment, no hydroxyapatite formation was observed after 30 days in SBF treatment. This comparison between the positive bioactive response of the hybrid scaffolds and the negative response of the BG free full gelatin scaffolds experiment confirmed the incorporation of the BG particulates improves the bioactivity of the gelatin hydrogels. It is important to remark that although the obtained gelatin/BG structures have a high volume percentage of porosity and macropores in the $100-500 \mu \mathrm{m}$ range size, there is another important requirement as the macropore cavities interconnection which has not been high enough and must be improved. In their respect encouraging results have been obtained using a PS/Aluminium mould configuration (Fig. 3d).

\section{Conclusions}

This work has shown the fabrication of homogeneous and reproducible gelatin/BG hybrid scaffolds. The porosity of the fabricated scaffolds was $95 \%$ and the macropore size was between $100-500 \mu \mathrm{m}$. The results indicated that the introduction of the BG particulates in the full gelatin scaffold promotes the bioactive response in vitro.

\section{AcKNowledgements}

We gratefully acknowledge the financial support provided by the Spanish Ministry of Science and Innovation (BIO2009-13903-C02-02), the Andalusian Ministry of Economy, Science and Innovation (Proyecto Excelencia
CTS-6681), S. B-G is a fellow from the Andalusian Government Predoctoral Programme.

\section{REFERENCES}

1. Azami M, Moztarzadeh F, Tahriri M. (2010) Preparation, characterization and mechanical properties of controlled porous gelatin/hydroxyapatite nanocomposite through layer solvent casting combined with freeze-drying and lamination techniques. J Porous Mater 17:313-320

2. Fratzl P, Weinkamer R. (2007) Nature's hierarchical materials. Progress in Materials Science 57:1263-1334

3. Engel E, Castaño O, Salvagni E, Ginebra M, Planell (2009) J. Biomaterials for Tissue Engineering of Hard Tissues. Springer, Brighton

4. Chevalier J, Gremillard L. New Trends in Ceramics for Orthopedics.

5. Jones JR. (2013) Review of bioactive glass - from Hench to hybrids. Acta Biomaterialia 9:4457-4486

6. Hench L. (2006) The story of Bioglass. Journal of materials science. Materials in medicine 17:967-78.

7. Hench L. (1998) Bioceramics. J Am Ceram Soc 8:1705-1728.

8. Rahaman M, Day D, Bal BS, Fu Q, Jung S, Bonewald L, et al. (2011) Bioactive glass in tissue engineering. Acta Biomaterialia 7:2355-73.

9. Mozafari M, Moztarzadeh F, Rabiee M, Azami M, Maleknia S. (2010) Development of macroporous nanocomposite scaffolds of gelatin/bioactive glass prepared through layer solvent casting combined with lamination technique for bone tissue engineering. Ceram Int 36:2431-2439.

10. Van Vlierberghe S, Cnudde V, Dubruel P, Masschaele B, Cosijns A. (2007) Porous gelatin hydrogels: 1 . Cryogenic formation and structure analysis. Biomacromolecules 8:331-337.

11. O'Brien F, Harley B, Yannas I, Gibson L. (2004) Influence of freezing rate on pore structure in freeze-dried collagen-GAG scaffolds. Biomaterials 25:1077-86.

12. Caliari S, Harley BAC. (2011) The effect of anisotropic collagenGAG scaffolds and growth factor supplementation on tendon cell recruitment, alignment, and metabolic activity. Biomaterials 32:53305340

13. Davidenko N, Gibb T, Schuster C, Best SM, Campbell JJ, Watson CJ, et al. (2012) Biomimetic collagen scaffolds with anisotropic pore architecture. Acta Biomaterialia 8:667-76

14. Wu X, Liu Y, Li X, Wen P, Zhang Y, Long Y, et al. (2010) Preparation of aligned porous gelatin scaffolds by unidirectional freezedrying method. Acta Biomaterialia 6:1167-77

15. Yan X, Yu C, Zhou X, Tang J, et al. (2004) Highly ordered mesoporous bioactive glasses with superior in vitro bone-forming bioactivities. Angew Chem Int Ed Engl. 43:5980-5984

16. Kokubo T, Takadama H. (2006) How useful is SBF in predicting in vivo bone bioactivity. Biomaterials 27:2907-2915

17. Yan X, Deng H, Huang X, Lu G, Qiao S. (2005) Mesoporous bioactive glasses. I. Synthesis and structural characterization. J Non Cryst Solids 351:3209-3217

18. Zhao S, Li Y, Li D. (2011) Synthesis of CaO-SiO2-P2O5 mesoporous bioactive glasses with high $\mathrm{P} 2 \mathrm{O} 5$ content by evaporation induced self assembly process. J Mater Sci Mater Med. 22:201-208

19. HollingerJO, Brekke J, Gruskin E, Lee D. (1996) Role of Bone substitutes. Clin Orthop Relat Res 324:55-65.

20. Querido W, Abracado LG, Rossi AL, Campos APC, Abraçado LG, Farina M, et al. (2011) Ultrastructural and mineral phase characterization of the bone-like matrix assembled in F-OST osteoblast cultures. Calcif Tissue Int 89:358-71. 